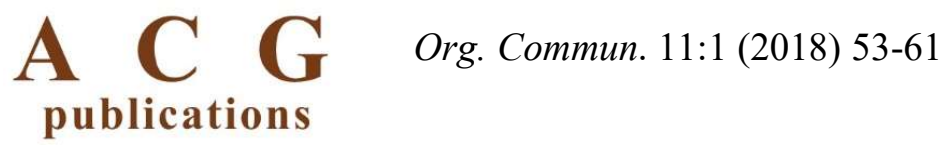

organic communications

\title{
Synthesis of natural phenylpropanoid esters via conventional chemical reactions
}

\author{
Flávio Valadares P. Borges $\odot^{1}$, Roberto Mioso $\odot^{2 *}$, Luíz André A. Silva $\odot^{1}$, \\ José Maria Barbosa-Filho ${ }^{1}$, Gabrielly Diniz Duarte $\odot^{3}$ \\ and Luis Cezar Rodrigues ${ }^{4}$
}

${ }^{1}$ Post-Graduate Program in Natural Products and Bioactives, Federal University of Paraíba, João Pessoa, 58051-900, PB, Brazil

${ }^{2}$ Department of Chemistry, University of Las Palmas de Gran Canaria, Las Palmas de Gran Canaria, 35017, Spain

${ }^{3}$ Department of Biotechnology, Federal University of Paraíba, João Pessoa, 58051-900, PB, Brazil

${ }^{4}$ Post-Graduate Program in Development and Technological Innovation in Medicines, Federal University of Paraíba, João Pessoa, 58051-900, PB, Brazil

(Received November 30,2017; Revised February 19, 2018; Accepted February 19, 2018)

\begin{abstract}
Using classical reactions, the synthesis of seven natural esters was described, including for the first time the synthesis of four natural phenylpropanoid esters-compounds that have demonstrated promising bioactivity, proven by preliminary studies using samples obtained from natural sources. Applying the Wittig reaction, cis- and trans-bornyl ferulates were obtained, in an unusual manner, which established an alternative for the preparation of phenylpropanoid esters, especially in the synthesis of phenolic esters of tertiary alcohols such as the $\alpha$-terpinyl trans-caffeate. The compounds obtained were identified and characterized by ${ }^{1} \mathrm{H}-\mathrm{NMR}$ and ${ }^{13} \mathrm{C}-\mathrm{NMR}$ spectroscopy.
\end{abstract}

Keywords: Wittig reaction; esterification; phenylpropanoid esters. C2018 ACG Publication. All right reserved

\section{Introduction}

Phenylpropanoid esters are part of an important class of natural products. They are normally present in aromatic essential oils, distributed throughout a wide range of plant species, and they are often responsible for many biological activities, especially when the benzene ring is methoxylated and/or hydroxylated.

Recently, our research group isolated the esters (-)-bornyl trans- and cis-p-coumarate (1-2, Figure 1) from the hexane phase of the aerial parts of Verbesina macrophylla, ${ }^{1}$ which was the first time that these compounds had been found in this bushy plant of the Asteraceae family, commonly known in Brazil as "assa peixe". Similarly, the $\alpha$-terpinyl trans-caffeate (3, Figure 1) was isolated for the first time from the chloroformic extract of the dried powdered leaves of Rollinia leptopetala - a

\footnotetext{
* Corresponding author: E-Mail: robertomioso@yahoo.co.uk
} 
species from the Annonaceae family that is endemic to Brazil and commonly known as "pinha brava". ${ }^{2}$

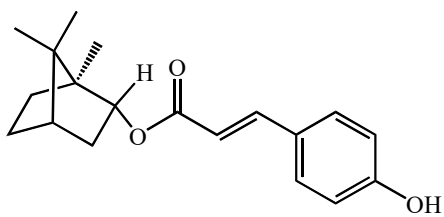

(-)-bornyl trans-p-cumarate (1)

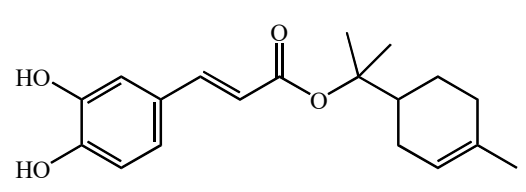

a-terpinyl trans-caffeate (3)

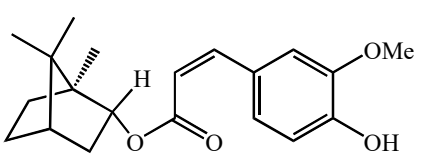

(-)-bornyl cis-ferulate (6)

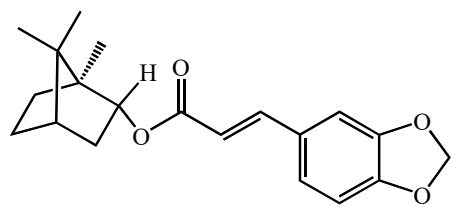

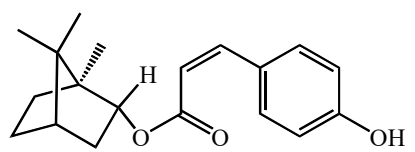

(-)-bornyl cis-p-cumarate (2)

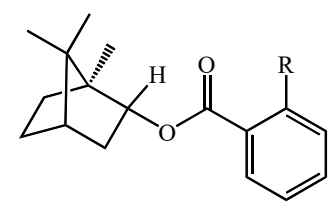

(-)-bornyl salicylate $\mathrm{R}=\mathrm{OH}(\mathbf{4})$ (-)-bornyl benzoate $\mathrm{R}=\mathrm{H}(\mathbf{5})$

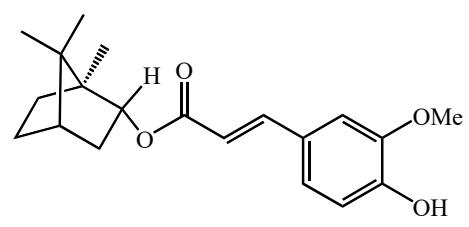

(-)-bornyl trans-ferulate (7)

(-)-bornyl trans-3,4-(methylenedioxy)cinnamate (8)

Figure 1. Natural benzoic and phenylpropanoid esters.

These naturally occurring compounds have displayed interesting biological activities. For example, (-)-bornyl salicylate (4, Figure 1) and (-)-bornyl trans-p-coumarate have been reported as having anti-inflammatory activity, ${ }^{3-7}$ while $(-)$-bornyl cis- $p$-coumarate has shown antifungal and anthelmintic activity, ${ }^{8}$ and, (-)-bornyl trans-p-coumarate has exhibited trypanosomicidal activity. ${ }^{9}$

Despite having a simple structure, so far no reports have been found in the literature for the synthesis of (-)-bornyl cis/trans-ferulate (5-7, Figure 1). This compound, which has anti-inflammatory activity, has already been found in various plants such as Verbesina rupestris, ${ }^{10}$ Notopterygium incisum, ${ }^{11}$ and Myodocarpus gracilis, ${ }^{12}$ among others. Similarly, the synthesis of the synthesis of (-)bornyl trans-3,4-(methylenedioxy)cinnamate (8, Figure 1) was described for the first time. It is a natural compound found once in Piper methysticum, and for which anti-inflammatory activity has been demonstrated, through the enzymatic inhibition of COX-1 and COX-2. ${ }^{13}$ Studies done with hydroxycinnamic esters of the (-)-borneol isolated from Verbesina turbacensis have also shown that these substances are able to inhibit cysteine protease. ${ }^{9}$

In view of the unprecedented character of these compounds, the extensive bioactivity history combined with their low concentration in natural media, and the characteristics of their production via predatory extraction from the natural environment, in this work synthetic attainment was proposed (which is more flexible, versatile, economic, and suitable), in order to obtain the necessary quantities and thus enable the execution of the in vivo pharmacological studies. 


\section{Experimental}

\subsection{Synthesis of (-)-bornyl salicylate (4): General Procedure I}

In a dry round-bottomed flask containing a stirring bar, (-)-borneol was weighed (1.54 g, 10 mmol, $1.0 \mathrm{Eq})$ and $10 \mathrm{~mL}$ of dry dioxane and salicylic acid $(1.38 \mathrm{~g}, 10 \mathrm{mmol}, 1.0 \mathrm{Eq})$ was added. A colorless homogeneous solution was formed and $0.5 \mathrm{~mL}$ of thionyl chloride was added dropwise, a heating blanket and a condenser were adapted, and after refluxing for $1 \mathrm{~h}$, the blanket was turned off, the dioxane was eliminated in a rotary evaporator, the residue was solubilized in $50 \mathrm{~mL}$ of ethyl acetate, and the resulting mixture was transferred to a separatory funnel, containing $50 \mathrm{~mL}$ of water, and extracted three times with $50 \mathrm{~mL}$ of ethyl acetate. The ethyl acetate phase was dried with anhydrous $\mathrm{MgSO}_{4}$, filtered, and the solvent eliminated in a rotary evaporator. The resulting residue was purified by column chromatography, with silica gel as the stationary phase and a hexane/ethyl acetate mixture, at a ratio of 9:1, as mobile phase. Thus, $2.3 \mathrm{~g}$ of a colorless viscous liquid was obtained at an $84 \%$ yield, which was subsequently proven to be (-)-bornyl salicylate.

${ }^{1} \mathrm{H}-\mathrm{NMR}\left(\delta, 200 \mathrm{MHz}, \mathrm{CDCl}_{3}\right): 8.08\left(1 \mathrm{H}, \mathrm{d}, \mathrm{H}-6{ }^{\prime}, J=8.0 \mathrm{~Hz}\right), 8,05\left(1 \mathrm{H}, \mathrm{d}, \mathrm{H}-2^{\prime}, J=8.0 \mathrm{~Hz}\right)$, 7.49 (2H, t, H-3'/5', $J=8.0 \mathrm{~Hz}$ ), 7.44 (1H, t, H-4', $J=8.0 \mathrm{~Hz}$ ), 5.10 (1H, m, H-2"), 2.47 (1H, m, H-3"b), $2.12(1 \mathrm{H}, \mathrm{m}, \mathrm{H}-6 " \mathrm{~b}), 1.73$ (1H, m, H-5"b), 1.66 (1H, s, H-4"), $1.42(1 \mathrm{H}, \mathrm{m}, \mathrm{H}-5 " \mathrm{a}), 1.32(1 \mathrm{H}, \mathrm{m}, \mathrm{H}-$ 6"a), 1.12 (1H, dd, H-3"a, $J=15 \mathrm{~Hz}$ and $3.5 \mathrm{~Hz}), 0.97$ (3H, s, H-8"), $0.91(3 \mathrm{H}, \mathrm{s}, \mathrm{H}-9 "), 0.88$ (3H, s, H10 "). ${ }^{13} \mathrm{C}-\mathrm{NMR}\left(\delta, 50.30 \mathrm{MHz}, \mathrm{CDCl}_{3}\right): 166.84(\mathrm{C} 1), 132.81\left(\mathrm{C} 4{ }^{\prime}\right), 130.93\left(\mathrm{C} 1^{\prime}\right), 129.56\left(\mathrm{C}^{\prime} / 6^{\prime}\right)$, 128.38 (C3'/5'), 80.55 (C2"), 49.16 (C1"), 47.95 (C7"), 45.03 (C4"), 36.99 (C3"), 28.19 (C5"), 27.46 (C6"), 19.82 (C9"), 19.01 (C8"), 13.72 (C10").

\section{Synthesis of (-)-bornyl benzoate (5)}

Following general procedure I, using benzoic acid and (-)-borneol, $2.1 \mathrm{~g}(81 \%)$ of a colorless, oily liquid was obtained, which was proven to be (-)-bornyl benzoate.

${ }^{1} \mathrm{H}-\mathrm{NMR}\left(\delta, 200 \mathrm{MHz}, \mathrm{CDCl}_{3}\right): 8.17\left(1 \mathrm{H}, \mathrm{d}, \mathrm{H}-6{ }^{\prime}, J=8.0 \mathrm{~Hz}\right), 7.99\left(1 \mathrm{H}, \mathrm{d}, \mathrm{H}-2^{\prime}, J=8.0 \mathrm{~Hz}\right)$, $7.53\left(2 \mathrm{H}, \mathrm{t}, \mathrm{H}-3^{\prime} / 5^{\prime}, J=8.0 \mathrm{~Hz}\right), 7.41\left(1 \mathrm{H}, \mathrm{t}, \mathrm{H}-4^{\prime}, J=8.0 \mathrm{~Hz}\right), 5,00\left(1 \mathrm{H}, \mathrm{m}, \mathrm{H}-2^{\prime \prime}\right), 2.41\left(1 \mathrm{H}, \mathrm{t}, \mathrm{H}-3^{\prime \prime} \mathrm{b}\right)$, 2.08 (1H, m, H-6"b), 1.78 (1H, m, H-5"b), $1.71(1 \mathrm{H}, \mathrm{t}, \mathrm{H}-4 ", J=4.5 \mathrm{~Hz}), 1.40$ (1H, m, H-5"a), 1.30 (1H, m, H-6"a) 1.06 (1H, dd, H-3"a, $J=15 \mathrm{~Hz}$ and $3.5 \mathrm{~Hz}$ ), 0.92 (3H, s, H-8"), 0.89 (3H, s, H-9"), 0.88 $\left(3 \mathrm{H}, \mathrm{s}, \mathrm{H}-10^{\prime \prime}\right) .{ }^{13} \mathrm{C}-\mathrm{NMR}\left(\delta, 50.30 \mathrm{MHz}, \mathrm{CDCl}_{3}\right): 166.68(\mathrm{C} 1), 132.50\left(\mathrm{C} 4^{\prime}\right), 130.76\left(\mathrm{Cl}^{\prime}\right), 129.40$ (C2'/6'), 128.22 (C3'/5'), 80.39 (C2"), 48.92 (C1"), 47.79 (C7"), 44.67 (C4"), 36.82 (C3"), 28.03 (C5"), 27.30 (C6"), 19.66 (C9"), 18.83 (C8"), 13.56 (C10").

\section{Synthesis of (-)-bornyl trans-p-hydroxycoumarate (1)}

Following general procedure I, using trans-p-hydroxycoumaric acid and (-)-borneol, $0.9 \mathrm{~g}$ $(60 \%)$ of (-)-bornyl trans-p-hydroxycoumarate was obtained.

${ }^{1} \mathrm{H}-\mathrm{NMR}\left(\delta, 200 \mathrm{MHz}, \mathrm{CDCl}_{3}\right): 7.62(1 \mathrm{H}, \mathrm{d}, \mathrm{H}-3, J=15.9 \mathrm{~Hz}), 7.43\left(1 \mathrm{H}, \mathrm{s}, \mathrm{H}-2^{\prime} / 6^{\prime}\right), 6.87(1 \mathrm{H}$, d, H-3'/5', $J=8.0 \mathrm{~Hz}), 6.33(1 \mathrm{H}, \mathrm{d}, \mathrm{H}-2, J=16 \mathrm{~Hz}), 5.00\left(1 \mathrm{H}, \mathrm{ddd}, \mathrm{H}-2^{\prime \prime} J=10.0 \mathrm{~Hz}, 5.5 \mathrm{~Hz}, 2.0 \mathrm{~Hz}\right)$, $2.42(1 \mathrm{H}, \mathrm{m}, \mathrm{H}-3 " \mathrm{~b}), 2.05$ (1H, m, H-6"b), 1.78 (1H, m, H-5"b), 1.71 (1H, t, H-4", $J=4.5 \mathrm{~Hz}), 1.40-$ $1.32(1 \mathrm{H}, \mathrm{m}, \mathrm{H}-5 " \mathrm{a}), 1.30-1.25(1 \mathrm{H}, \mathrm{m}, \mathrm{H}-6 " \mathrm{a}), 1.06(1 \mathrm{H}, \mathrm{dd}, \mathrm{H}-3 \mathrm{a} \mathrm{a}, J=15.0 \mathrm{~Hz}$ and $3.5 \mathrm{~Hz}), 0.93(3 \mathrm{H}$, s, H-8"), 0.89 (3H, s, H-9"), 0.88 (3H, s, H-10"). ${ }^{13} \mathrm{C}-\mathrm{NMR}\left(\delta, 50.30 \mathrm{MHz}, \mathrm{CDCl}_{3}\right): 168.34(\mathrm{C} 1)$, 158.16 (C4'), 144.48 (C3), 130.02 (C2'/C6'), 126.95 (C1'), 115.95 (C2), 115.88 (C3'/5'), 80.30 (C2"), 48.95 (C1"), 47.84 (C7"), 44.93 (C4"), 36.83 (C3"), 28.04 (C5"), 27.26 (C6"), 19.72 (C9"), 18.06 (C8"), $13.55\left(\mathrm{C} 10^{\prime \prime}\right)$. 


\section{Synthesis of (-)-bornyl trans-3,4-(methylenedioxy)cinnamate (8)}

Following general procedure I, using trans-3,4-(methylenedioxy)cinnamic acid and (-)borneol, $0.85 \mathrm{~g}(52 \%)$ of a white solid was obtained, which was proven to be (-)-bornyl trans-3,4(methylenedioxy)cinnamate.

${ }^{1} \mathrm{H}-\mathrm{NMR}\left(\delta, 200 \mathrm{MHz}, \mathrm{CDCl}_{3}\right): 7.57(1 \mathrm{H}, \mathrm{d}, \mathrm{H}-3, J=15.9 \mathrm{~Hz}), 7.04\left(1 \mathrm{H}, \mathrm{s}, \mathrm{H}-2{ }^{\prime}\right), 7.00(1 \mathrm{H}, \mathrm{d}$, H-6', $J=8.0 \mathrm{~Hz}), 6.80\left(1 \mathrm{H}, \mathrm{d}, \mathrm{H}-5{ }^{\prime}, J=8.0 \mathrm{~Hz}\right), 6.29(1 \mathrm{H}, \mathrm{d}, \mathrm{H}-2, J=15.9 \mathrm{~Hz}), 5.99\left(2 \mathrm{H}, \mathrm{s}, \mathrm{H}-7^{\prime \prime}\right), 5.0$ $\left(1 \mathrm{H}, \mathrm{d}, \mathrm{H}-2^{\prime}, J=9.8 \mathrm{~Hz}\right), 2.40(1 \mathrm{H}, \mathrm{dd}, \mathrm{H}-3, J=13.6 \mathrm{~Hz}$ and $10.0 \mathrm{~Hz}), 2.05(1 \mathrm{H}, \mathrm{m}, \mathrm{H}-6 " \mathrm{~b}), 1.77(1 \mathrm{H}$, d, H-5"b, $J=3.8 \mathrm{~Hz}), 1.70(1 \mathrm{H}, \mathrm{t}, \mathrm{H}-4 ", J=3,5 \mathrm{~Hz}), 1.35(1 \mathrm{H}, \mathrm{m}, \mathrm{H}-5 " \mathrm{a}), 1.05(1 \mathrm{H}, \mathrm{dd}, \mathrm{H}-3$ "a, $J=13.8$ $\mathrm{Hz}$ and $3.0 \mathrm{~Hz}), 0.94$ (3H, s, H-8"), 0.89 (3H, s, H-9"), 0.87 (3H, s, H-10"). ${ }^{13} \mathrm{C}-\mathrm{NMR}(\delta, 50.30 \mathrm{MHz}$, $\left.\mathrm{CDCl}_{3}\right)$ : $167.39(\mathrm{C} 1), 149.44\left(\mathrm{C}^{\prime}\right), 148.29\left(\mathrm{C}^{\prime}\right), 143.83$ (C3), $128.97\left(\mathrm{Cl}^{\prime}\right), 124.22\left(\mathrm{C}^{\prime}\right), 116.73$ (C2), 108.44 (C5'), 106.47 (C2'), 101.46 (C7'), 79.80 (C2"), 48.90 (C1"), 47.81 (C7"), 44.95 (C4"), 36.83 (C3"), 28.04 (C5"), 27.22 (C6"), 19.70 (C9"), 18.85 (C8"), 13.50 (C10").

\subsection{Synthesis of (-)-bornyl trans/cis-ferulate: General Procedure II}

In a reaction tube with a dry side exit, (-)-borneol $(0.5 \mathrm{~g}, 3.2 \mathrm{mmol}, 1.0 \mathrm{Eq})$ was weighed and $2.5 \mathrm{~mL}$ of dry dioxane was added, which formed a colorless homogeneous solution, into which chloroacetyl chloride $(0.4 \mathrm{~g}, 3.5 \mathrm{mmol}, 1.1 \mathrm{Eq})$ was added. The reaction tube was transferred to an oil bath on a heating plate, a refrigerated cold finger was adapted, and reflux was maintained for $2 \mathrm{~h}$. Triphenylphosphine $(0.92 \mathrm{~g}, 3.5 \mathrm{mmol}, 1.1 \mathrm{Eq})$ was then added and reflux was maintained for an additional $1.5 \mathrm{~h}$. Solid potassium tert-butoxide $(0.39 \mathrm{~g}, 3.5 \mathrm{mmol}, 1.1 \mathrm{Eq})$ was added and the mixture was magnetically stirred for $1 \mathrm{~h}$. Solid vanillin $(0.49 \mathrm{~g}, 3.2 \mathrm{mmol}, 1.0 \mathrm{Eq})$ was then added and the reaction mixture was again heated to reflux for $2 \mathrm{~h}$. The heating was turned off, the dioxane eliminated in a rotary evaporator, the residue solubilized in $30 \mathrm{~mL}$ of diethyl ether, and the resulting mixture was transferred to a separatory funnel, containing $50 \mathrm{~mL}$ of brine, and extracted three times with $30 \mathrm{~mL}$ of diethyl ether, and then the ether phase was dried with anhydrous $\mathrm{MgSO}_{4}$ and filtered and the solvent eliminated in a rotary evaporator. The resulting residue was purified by preparative plate chromatography, with silica gel as the stationary phase and a hexane/ethyl acetate mixture, at a 9:1 ratio, as mobile phase. Thus, the following were obtained: $0.1 \mathrm{~g}$ of a colorless viscous liquid at a $10 \%$ yield, which was shown to be (-)-bornyl cis-ferulate; and $0.42 \mathrm{~g}$ of a white solid at a $40 \%$ yield, which was the (-)-bornyl trans-ferulate.

(-)-Bornyl cis-ferulate (6): ${ }^{1} \mathrm{H}-\mathrm{NMR}\left(\delta, 200 \mathrm{MHz}, \mathrm{CDCl}_{3}\right): 7.68(1 \mathrm{H}, \mathrm{d}, \mathrm{H}-2$ ', $J=2.0 \mathrm{~Hz}), 7.14$ $\left(1 \mathrm{H}, \mathrm{dd}, \mathrm{H}-6^{\prime}, J=8.0 \mathrm{~Hz}\right.$ and $\left.2.0 \mathrm{~Hz}\right), 6.89\left(1 \mathrm{H}, \mathrm{d}, \mathrm{H}-5^{\prime}, J=8.0 \mathrm{~Hz}\right), 6.81(1 \mathrm{H}, \mathrm{d}, \mathrm{H}-3, J=12.8 \mathrm{~Hz})$, $5.88(1 \mathrm{H}, \mathrm{d}, \mathrm{H}-2, J=12.0 \mathrm{~Hz}), 4.96(1 \mathrm{H}, \mathrm{ddd}, \mathrm{H}-2 ", J=9.2 \mathrm{~Hz} ; 3.4 \mathrm{~Hz}$ and $2.0 \mathrm{~Hz}), 2.40(1 \mathrm{H}, \mathrm{m}, \mathrm{H}-$ 3"b), 1.88 (1H, m, H-6"b), 1.81 (1H, m, H-5"b), 1.73 (1H, m, H-4"), 1.25 (1H, m, H-5"a), 1.21 (1H, m, H-6"a), 1.03 (1H, dd, H-3"a, $J=13.8 \mathrm{~Hz}$ and $2.0 \mathrm{~Hz}$ ), 0.91 (3H, s, H-8"), 0.86 (3H, s, H-9"), $0.82(1 \mathrm{H}$, s, H-10"). ${ }^{13} \mathrm{C}-\mathrm{NMR}\left(\delta, 50.30 \mathrm{MHz}, \mathrm{CDCl}_{3}\right): 167.03(\mathrm{C} 1), 146.96\left(\mathrm{C} 3^{\prime}\right), 146.02\left(\mathrm{C} 4{ }^{\prime}\right), 143.30(\mathrm{C} 3)$, 127.51 (C1'), 125.40 (C6'), 117.03 (C5'), 113.96 (C2'), 112.82 (C2), 79.76 (C2"), 56.09 (OMe), 48.91 (C1"), 47.93 (C7"), 45.04 (C4"), 36.89 (C3"), 28.14 (C5"), 27.22 (C6"), 19.88 (C9"), 19.02 (C8"), $13.28\left(\mathrm{C} 10^{\prime \prime}\right)$.

(-)-Bornyl trans-ferulate (7): ${ }^{1} \mathrm{H}-\mathrm{NMR}\left(\delta, 200 \mathrm{MHz}, \mathrm{CDCl}_{3}\right): 7.59(1 \mathrm{H}, \mathrm{d}, \mathrm{H}-3, J=16 \mathrm{~Hz}), 7.10$ $\left(1 \mathrm{H}, \mathrm{d}, \mathrm{H}-2^{\prime}, J=1.8 \mathrm{~Hz}\right), 7.05\left(1 \mathrm{H}, \mathrm{dd}, \mathrm{H}-6^{\prime}, J=7.8 \mathrm{~Hz}\right.$ and $\left.2.0 \mathrm{~Hz}\right), 6.88\left(1 \mathrm{H}, \mathrm{d}, \mathrm{H}-5^{\prime}, J=8.0 \mathrm{~Hz}\right), 6.32$ $(1 \mathrm{H}, \mathrm{d}, \mathrm{H}-2, J=16.0 \mathrm{~Hz}), 5.01(1 \mathrm{H}, \mathrm{ddd}, \mathrm{H}-2 " J=10.0 \mathrm{~Hz}, 6.0 \mathrm{~Hz}, 2.0 \mathrm{~Hz}), 2.41(1 \mathrm{H}, \mathrm{m}, \mathrm{H}-3 \mathrm{l}) \mathrm{b}), 2.04$ $(1 \mathrm{H}, \mathrm{m}, \mathrm{H}-6 " \mathrm{~b}), 1.78(1 \mathrm{H}, \mathrm{m}, \mathrm{H}-5 " \mathrm{~b}), 1.71(1 \mathrm{H}, \mathrm{t}, \mathrm{H}-4 ", J=4.0 \mathrm{~Hz}), 1.34(1 \mathrm{H}, \mathrm{m}, \mathrm{H}-5 \mathrm{a}), 1.29(1 \mathrm{H}, \mathrm{m}$, H-6"a), 1.05 (1H, dd, H-3"a, J=14.0 Hz and $2.0 \mathrm{~Hz}), 0.94\left(3 \mathrm{H}, \mathrm{s}, \mathrm{H}-8^{\prime \prime}\right), 0.89$ (3H, s, H-9"), $0.88(1 \mathrm{H}$, s, H-10"). ${ }^{13} \mathrm{C}-\mathrm{NMR}\left(\delta, 50.30 \mathrm{MHz}, \mathrm{CDCl}_{3}\right): 167.78$ (C1), 147.98 (C3'), 145.99 (C4'), 144.44 (C3), 127.19 (C1'), 123.15 (C6'), 116.16 (C5'), 114.82 (C2'), 109.43 (C2), 79.89 (C2"), 56.10 (OMe), 49.05 (C1"), 47.97 (C7"), 45.07 (C4"), 37.00 (C3"), 28.21 (C5"), 27.38 (C6"), 19.87 (C9"), 19.03 (C8"), $13.72\left(\mathrm{C} 10^{\prime \prime}\right)$. 


\section{Synthesis of $\alpha$-terpinyl chloroacetate}

In a dry round-bottomed flask containing a stirring bar, $\alpha$-terpineol $(1 \mathrm{~g}, 6.5 \mathrm{mmol}, 1.0 \mathrm{Eq})$ was weighed and $20 \mathrm{~mL}$ of dry dioxane was added to form a homogeneous colorless solution, to which sodium hydride $60 \%$ was added in mineral oil $(0.5 \mathrm{~g}, 6.5 \mathrm{mmol}, 1.0 \mathrm{Eq})$. A stirring plate was adapted and the solution was magnetically stirred for $4 \mathrm{~h}$, then the reaction mixture was transferred dropwise to another flask containing a stirring bar and a chloroacetyl chloride solution $(0.6 \mathrm{~mL}, 0.85$ $\mathrm{g}, 7.5 \mathrm{mmol}, 1.2 \mathrm{Eq})$ in $10 \mathrm{~mL}$ of dry dioxane. This new reaction mixture was magnetically stirred for $4 \mathrm{~h}$, then the dioxane was eliminated in a rotary evaporator, the residue was solubilized in $30 \mathrm{~mL}$ of $\mathrm{CH}_{2} \mathrm{Cl}_{2}$, and the resulting mixture was transferred to a separatory funnel, containing $50 \mathrm{~mL}$ of water, and extracted three times with $30 \mathrm{~mL}$ of $\mathrm{CH}_{2} \mathrm{Cl}_{2}$. The dichloromethane phase was dried with anhydrous $\mathrm{MgSO}_{4}$ and filtered, and the solvent eliminated in a rotary evaporator. The resulting residue was purified in column chromatography, with silica gel as stationary phase and a hexane/ethyl acetate mixture, at a ratio of 95:5, as mobile phase. Thus, $0.8 \mathrm{~g}$ of a slightly yellowish liquid was obtained at a yield of $53 \%$, which was shown to be $\alpha$-terpinyl chloroacetate.

${ }^{1} \mathrm{H}-\mathrm{NMR}\left(\delta, 200 \mathrm{MHz}, \mathrm{CDCl}_{3}\right): 5.33$ (1H, s, H6'), 3.94 (1H, s, H1), 2.02 (1H, m, H-4'), 1.94 $\left(1 \mathrm{H}, \mathrm{m}, \mathrm{H}-5^{\prime}\right), 1.81\left(1 \mathrm{H}, \mathrm{m}, \mathrm{H}-2^{\prime}\right), 1.62\left(3 \mathrm{H}, \mathrm{s}, \mathrm{H}-7^{\prime}\right), 1.46$ (3H, s, H-10'), $1.44\left(3 \mathrm{H}, \mathrm{s}, \mathrm{H}-9^{\prime}\right), 1.30(1 \mathrm{H}$, m, H-3'). ${ }^{13} \mathrm{C}-\mathrm{NMR}\left(\delta, 50.30 \mathrm{MHz}, \mathrm{CDCl}_{3}\right): 166.10(\mathrm{C} 2), 133.91\left(\mathrm{C} 1^{\prime}\right), 127.20(\mathrm{C} 1), 122.11$ (C6), 119.98 (C6'), 87.70 (C8'), 42.63 (C4'), 41.98 (C1), 30.67 (C2'), 26.22 (5'), 23.70 (C3'), 23.22 (C9'), $23.12\left(\mathrm{C} 10^{\prime}\right), 22.86\left(\mathrm{C} 7^{\prime}\right)$.

\section{Synthesis of $\alpha$-terpinyl trans-caffeate (3): General Procedure II}

Following general procedure II, using caffeic acid and $\alpha$-terpineol, $0.2 \mathrm{~g}(20 \%)$ of a viscous colorless liquid was obtained, which was shown to be $\alpha$-terpinyl trans-caffeate.

${ }^{1} \mathrm{H}-\mathrm{NMR}\left(\delta, 200 \mathrm{MHz}, \mathrm{CDCl}_{3}\right): 7.45(1 \mathrm{H}, \mathrm{d}, \mathrm{H}-7, J=16 \mathrm{~Hz}), 7.09(1 \mathrm{H}, \mathrm{d}, \mathrm{H}-2, J=2.0 \mathrm{~Hz})$, $6.93(1 \mathrm{H}, \mathrm{dd}, \mathrm{H}-6, J=2.0 \mathrm{~Hz}$ and $8.0 \mathrm{~Hz}), 6.85(1 \mathrm{H}, \mathrm{d}, \mathrm{H}-5, J=8.0 \mathrm{~Hz}), 6.17(1 \mathrm{H}, \mathrm{d}, \mathrm{H}-8, J=16 \mathrm{~Hz})$, $5.40\left(1 \mathrm{H}, \mathrm{s}, \mathrm{H}-6^{\prime}\right), 2.07$ (1H, m, H-4'), 1.98 (1H, m, H-5'), 1.79 (1H, m, H-2'), 1.65 (3H, s, H-7'), 1.52 $\left(3 \mathrm{H}, \mathrm{s}, \mathrm{H}-10^{\prime}\right), 1.49\left(3 \mathrm{H}, \mathrm{s}, \mathrm{H}-9\right.$ '), $1.26\left(1 \mathrm{H}, \mathrm{m}, \mathrm{H}-3^{\prime}\right) .{ }^{13} \mathrm{C}-\mathrm{NMR}\left(\delta, 50.30 \mathrm{MHz}, \mathrm{CDCl}_{3}\right): 167.56(\mathrm{C} 9)$, 146.59 (C4), 144.30 (C3), 144.13 (C7), 133.97 (C1') 127.20 (C1), 122.11 (C6), 120.23 (C6'), 116.98 (C8), 115.32 (C5), 114.17 (C2), 85.63 (C8'), 42.75 (C4'), 30.85 (C2'), 26.41 (5'), 23.92 (C3'), 23.49 (C9'/C10'), 23.36 (C7').

\section{Results and Discussion}

There is a wide range of strategies for the synthesis of esters, and in the specific case of phenylpropanoids it would be no different. However, two main features differentiate these aromatic esters from their similar aliphatic and alicyclic counterparts. The first is in relation to the presence of the conjugated propenoid system, which can transmit to the terminal ester group the influence of the substituents attached to the benzene. The second difference concerns the possible presence of phenolic hydroxyls, which in many cases require the use of protector groups.

In addition to the classical direct esterification, there are numerous ways to prepare phenylpropanoid esters, a highlight being the Mizoroki-Heck reaction, which requires the prior preparation of a suitable acrylic ester. Thus, it is possible in some cases to circumvent the need to use protector groups for phenolic hydroxyl. ${ }^{14}$ The use of Knoevenagel-Dobner condensation is also common, in which it is possible to obtain tertiary alcohol ester, making it react with a beta-diester like Meldrum acid in the presence of a suitable phenolic aldehyde. ${ }^{15-16}$

In this work, the direct esterification of non-free phenolic phenylpropanoid acids with primary and secondary alcohols has proven to be quite advantageous. The trans-3,4-(methylenedioxy)- 
cinnamate of (-)-borneol (Entry 1, Table 1) was obtained by direct esterification of (-)-borneol with trans-3,4-(methylenedioxy)cinnamic acid in the presence of a small amount of thionyl chloride. Using the same protocol, (-)-bornyl trans-p-hydroxycoumarate and (-)-bornyl salicylate were obtained at a good yield (Entries 2 and 3, Table 1).

A common alternative in the production of esters is to convert carboxylic acids into acid chlorides or acid anhydrides, which are more reactive. Thionyl chloride not only contributes to converting the phenylpropanoid acid in the corresponding acid chloride, it also eliminates the residual water and the water formed during esterification. Thus, thionyl chloride represents a way of producing anhydrous hydrochloric acid, which acts as a catalyst and protonates carbonylic oxygen and contributes to the esterification reaction. Using benzoyl chloride and (-)-borneol, (-)-bornyl benzoate was obtained, which is a natural ester found in the essential oil of Alpinia galangal (Entry 4, Table 1). ${ }^{17}$

Table 1. Synthesis of the cis/trans bornyl ferulate via Wittig reaction.
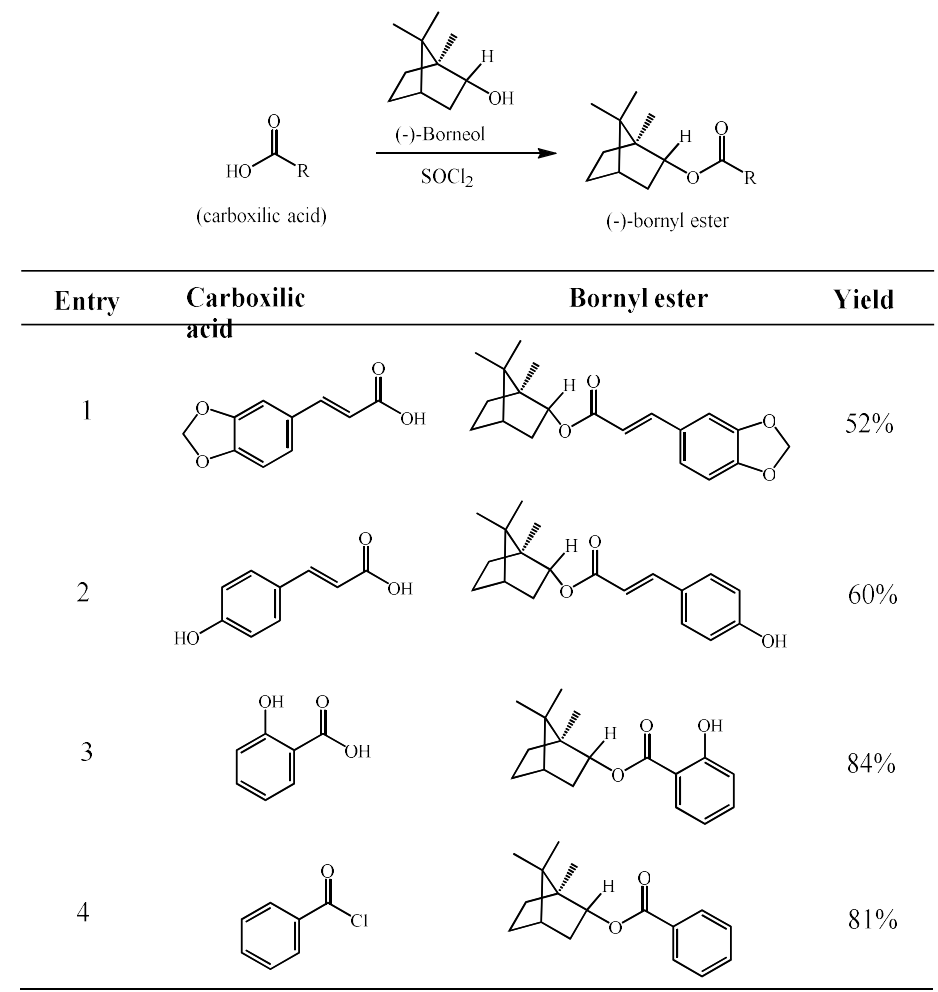

When the acids present free phenolic hydroxyls, and spatially-shielded tertiary alcohols like $\alpha$ terpineol are used, esterification normally demands more energetic conditions, which results in the formation of by-products, thus leading to low yields and difficulties in the purification of the desired ester. In order to avoid these inconveniences, it is usually recommended to protect the phenolic groups before proceeding with esterification.

The use of protector groups requires two additional reactions - one for protection and the other for deprotection - and involves the use of additional reagents, which besides being expensive also cause a reduction in the total yield. Despite knowing that phenolic groups are barely tolerated in the Wittig reactions, it was decided to investigate their use for obtaining unsaturated alpha-beta esters. Low-yield reactions could probably be compensated by the reduction in the number of steps needed to obtain the final product. Using a suitable aldehyde and the corresponding alkyl chloroacetate, obtainment of the desired phenylpropanoid esters was proposed.

In order to test this proposal, bornyl ferulate was initially prepared - in this case, bornyl chloroacetate was treated with triphenylphosphine, which resulted in the respective phosphonium salt, and in the presence of potassium tert-butoxide in dry dioxane this led to the formation of the corresponding triphenyl phosphonium ylide (often called a Wittig reagent), which provided the bornyl 
trans/cis ferulate mixture at a ratio of $8: 2$ and at an acceptable yield, when treated with anhydrous vanillin (see Scheme 1).

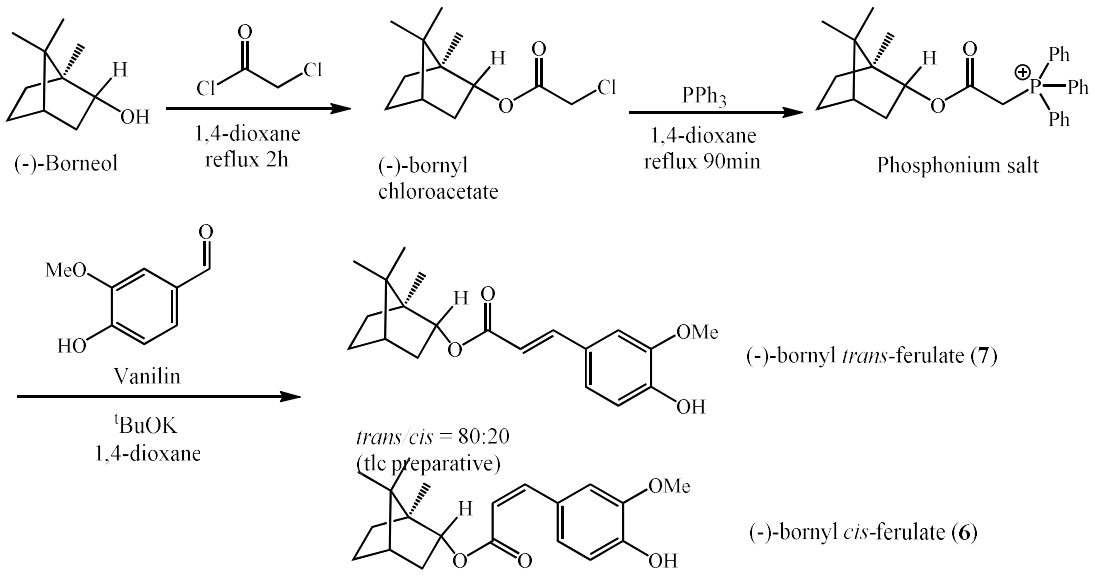

Scheme 1. Synthesis of the cis/trans bornyl ferulate via Wittig reaction.

With the good results confirmed, the next step was to apply the same methodology to the esterification of caffeic acid, which has two phenolic free hydroxyls groups, with the $\alpha$-terpineol that is a tertiary alcohol.

The $\alpha$-terpinyl chloroacetate was obtained by direct esterification of the sodium salt of the $\alpha$ terpineol with chloroacetyl chloride, and the resulting chloroester was treated with triphenyl phosphine to furnish phosphonium salt, which in the presence of catechol aldehyde and potassium tert-butoxide selectively provided the trans isomer of the $\alpha$-terpineol caffeate, whose synthesis was described for the first time. Using $\alpha$-terpineol sodium salt, it was also possible to prepare $\alpha$-terpinyl benzoate, which is a natural aromatic substance present in Perilla frutescens (see Scheme 2). ${ }^{18}$

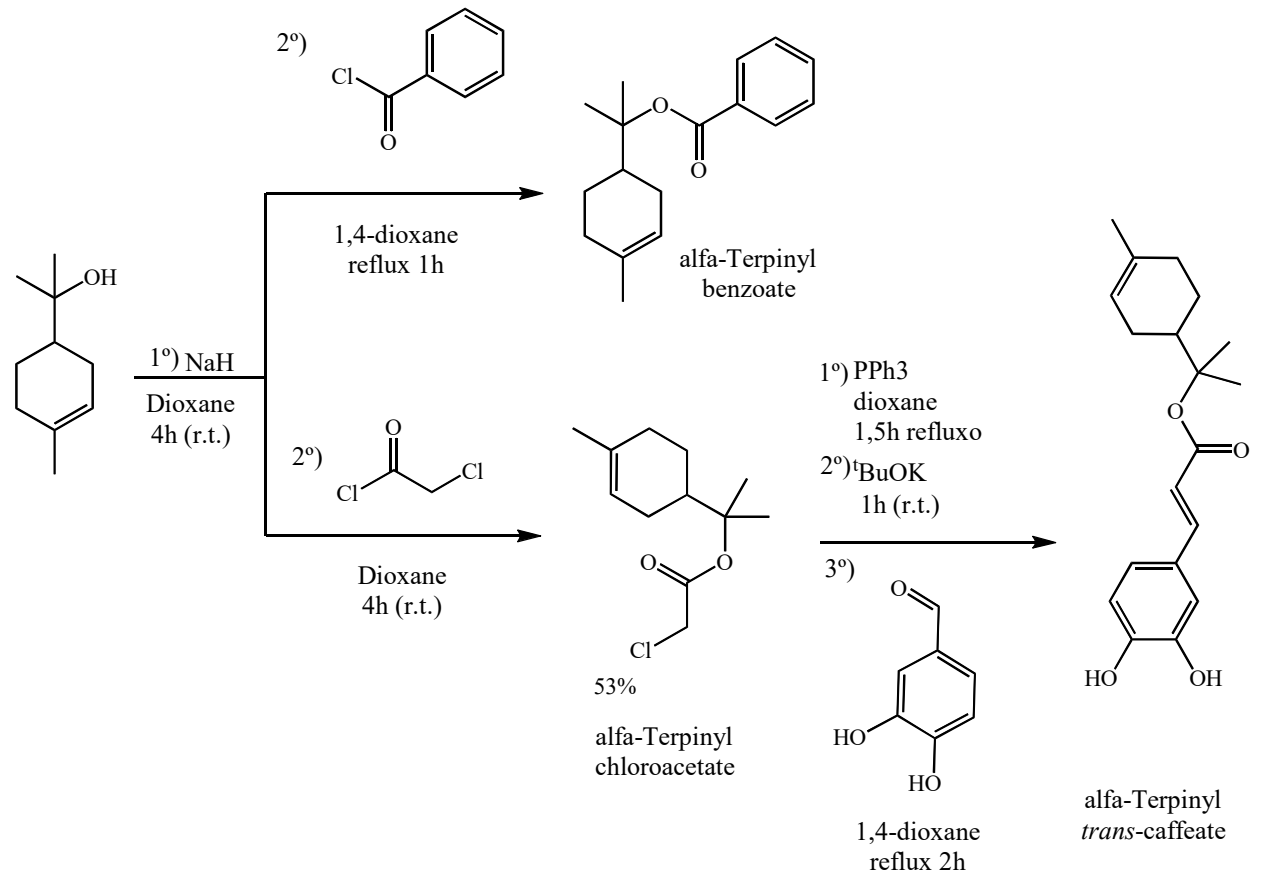

Scheme 2. Synthesis of the $\alpha$-terpineol trans-caffeate via Wittig reaction. 


\section{Conclusion}

Many important natural phenylpropanoids which possess diverse and promising bioactivity are the subject of relevant studies and publications. Despite the relative structural simplicity, several of these bioactives have not yet been synthesized, and those that have been studied in vivo, and which normally require significant amounts of the active ingredient, are unviable. Thus, this work contributes to the offer of alternative routes to extraction activity, by describing for the first time the synthesis of some phenylpropanoids.

Due to the difficulties in obtaining hydroxy phenylpropanoid esters from tertiary alcohols via direct esterification reaction, this proposal represents an alternative to be explored for cases in which other methods do not provide better results. Instead of phenylpropanoid acids, which are generally more expensive, the Wittig reaction uses aldehydes, which are generally more affordable. Similarly, the esterification reaction may be done in the presence of an excess of low-cost chloroacetyl chloride, which can be used as solvent. Another benefit includes avoiding the presence of phenolic hydroxyls at the moment of esterification, which only occurs in the presence of acid chloride and the corresponding alcohol. Another thing to be taken into account is that the phosphonium salt formed is a stable solid that can be stored and used when needed.

\section{Acknowledgements}

The authors would like to thank the Brazilian Ministry of Education and Culture (MEC) and the Coordination for the Improvement of Higher Education Personnel (CAPES) for the MSc. fellowships granted to F.V.P.B. and L.A.A.S, respectively. We also would like to thank the Centre for Characterization and Analysis of the Federal University of Paraíba (NUCAL) for technical assistance and NMR spectroscopy.

\section{Supporting Information}

Supporting information accompanies this paper on http://www.acgpubs.org/OC

\section{ORCID}

Flávio Valadares P. Borges: 0000-0002-2205-0688

Roberto Mioso: 0000-0003-1369-2037

Luiz André de Araújo Silva: 0000-0001-9212-2352

José Maria Barbosa-Filho: 0000-0002-9567-4096

Gabrielly Diniz Duarte: 0000-0001-6185-7647

Luis Cezar Rodrigues: 0000-0003-0276-842X

\section{References}

[1] Maia, G. L. A.; Tenório-Souza, F.H.; Costa, V. C. O.; Tavares, J. F.; Barbosa-Filho, J. M. In Anais da $34^{a}$ Reunião Anual da Sociedade Brasileira de Química, Florianópolis, Brasil, 2011.

[2] Costa, V. C. O. C.; Tavares, J. F.; Queiroga, C. S.; Castello-Branco, M. V. S.; Diniz, M. F. F. M.; Lima, C. U. G. B.; Santos, B. V. O.; Pita, J. C. L. R., Silva, M. S.; Sette, I. M. F. Chemical constituents of the leaves from Rollinia leptopetala. Quim. Nova 2012, 35, 138-142.

[3] Lobitz, G. O.; Heilmann, J.; Zschocke, S.; Tamayo-Castillo, G.; Bauer, R.; Merfort, I. Bornyl cinnamate derivatives with anti-inflammatory activity from Verbesina turbacensis. Pharm. Pharmacol. Lett. 1998, 8, 115-118.

[4] Maldonado, E.; Apan, R.; Teresa, M.; Perez-Castorena, A.L. Anti-inflammatory activity of phenyl propanoids from Coreopsis mutica var. mutica. Planta Med. 1998, 64, 660-661.

[5] Melzig, M. F.; Loser, B.; Lobitz, G. O.; Tamayo-Castillo, G.; Merfort, I. Inhibition of granulocyte elastase activity by caffeic acid derivatives. Pharmazie 1999, 54, 712-712.

[6] Siedle, B.; Murillo, R.; Hucke, O.; Labahn, A.; Merfort, I. Structure activity relationship studies of cinnamic acid derivatives as inhibitors of human neutrophil elastase revealed by ligand docking calculations. Pharmazie 2003, 58, 337-339. 
[7] Vasconcelos, R. M. C.; Leite, C. F.; Leite, J. A.; Mascarenhas, S. R.; Rodrigues, L. C.; Piuvezam, M. R. Synthesis, acute toxicity and anti-inflammatory effect of bornyl salicylate, a salicylic acid derivative. Immunopharm. Immunot. 2012, 34, 1028-1038.

[8] Akendengue, B.; Champy, P.; Nzamba, J.; Roblot, F.; Loiseau, P. M.; Bories, C. Antifungal and anthelmintic activities of Cleistopholis patens (Annonaceae). Planta Med. 2009, 75, 1143-1145.

[9] Ogungbe, I. V.; Crouch, R. A.; Haber, W. A.; Setzer, W. N. Phytochemical investigation of Verbesina turbacensis Kunth: trypanosome cysteine protease inhibition by (-)-bornyl esters. Nat. Prod. Commun. 2010, 5, 1161-1166.

[10] Box, V. G. S.; Chan, W. R. Terpenoids from Verbesina rupestris. Phytochemistry 1975, 14, 583-583.

[11] Zschocke, S.; Lehner, M.; Bauer, R. 5-Lipoxygenase and cyclooxygenase inhibitory active constituents from Qianghuo (Notopterygium incisum). Planta Med. 1997, 63, 203-206.

[12] Montagnac, A.; Provost, J. P.; Litaudon, M.; Pais, M. Antimitotic and cytotoxic constituents of Myodocarpus gracilis. Planta Med. 1997, 63, 365-366.

[13] Wu, D.; Nair, M. G.; DeWitt, D.L. Novel compounds from Piper methysticum Forst (Kava Kava) roots and their effect on cyclooxygenase enzyme. J. Agric. Food Chem. 2002, 50, 701-705.

[14] Declerck, V.; Colacino, E.; Bantreil, X.; Martinez, J.; Lamaty, F. Poly(ethylene glycol) as reaction medium for mild Mizoroki-Heck reaction in a ball-mill. Chem. Comm. 2012, 48, 11778-11780.

[15] Hu, W. -X.; Xia, C. -N.; Wang, G. -H.; Zhou, W. One-pot preparation of caffeic acid esters from 3,4dihydroxybenzaldehyde. J. Chem. Res. 2006, 9, 586-588.

[16] Magolan, J.; Coster, M. J. Total synthesis of (+)-angelmarin. J. Org. Chem. 2009, 74, 5083-5086.

[17] Raina, V. K.; Srivastava, S. K.; Syamasunder, K. V. The essential oil of 'greater galangal' [Alpinia galanga (L.) Willd.] from the lower Himalayan region of India. Flavour Frag. J. 2002, 17, 358-360.

[18] Dong, L.; Zhou, L. Pharmacological research about Perilla frutescens. Zhongguo Yaoye 2008, 17, 61-62.

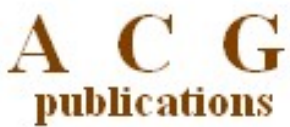

(C) 2018 ACG Publications 